Objectives: To evaluate the effects of short-term beetroot juice supplementation on endothelial function in patients with RA and COPD.

Methods: A total of 28 patients, 9 with RA, 9 with COPD and 10 healthy controls participated in the study. Following consent, they were asked to report at the testing venue (Ultrasonography Laboratory, General Hospital of Trikala) early in the morning, following an overnight fast. Demographic and disease characteristics were recorded; height, weight, classical risk factor for cardiovascular disease and body composition were assessed. Endothelial function was assessed using flow mediated vasodilatation. They randomly received either beetroot (experimental leg) or blackcurrant juice (control leg), which they consumed daily for two weeks. Thereafter they were re-evaluated. Following a two-week washout period, they crossed over to the other leg of the study.

Results: There was no difference in pre-occlusion diameter between any of the time-points. Endothelial function was significantly improved following beetroot juice consumption for both patient groups (RA: $2.6 \%$ [0.9 - 6.2] vs $10.7 \%$ [6.2 11.7]; $p=0.013$. COPD: $3.4 \%[1.2-4.8]$ vs $7.8 \%$ [3.6 - 10.2]; $p=0.034$ ) while it remained relatively unaffected by blackcurrant consumption (Overall: $3.9 \%$ [0 $5.1]$ vs $4.2 \%[2.3-6.1] ; p=0.26)$.
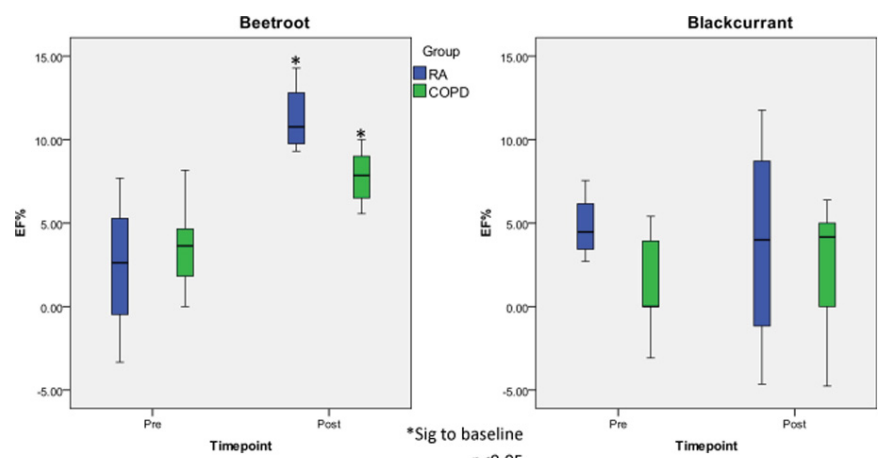

Figure 1

Conclusions: A two week consumption of beetroot juice seems to be able to improve endothelial function among patients with RA and COPD. This could elicit significant health benefits. Further research to investigate the benefits of longer-term use on endothelial function and related cardiovascular health, as well as disease symptoms, and quality of life is advocated.

References:

[1] Moncada, S. and Higgs, E.A. The discovery of nitric oxide and its role in vascular biology. British Journal of Pharmacology 2006, 147: S193-S201.

[2] Sandoo, A. et al. Vascular function and morphology in rheumatoid arthritis: a systematic review. Rheumatology 2011, 50 (11): 2125-2139.

[3] Clarenbach, C.F. Determinants of endothelial function in patients with COPD. European Respiratory Journal 2013, 42 (5): 1194-1204.

[4] Clifford, T. et al. The Potential Benefits of Red Beetroot Supplementation in Health and Disease. Nutrients 2015, 7.4: 2801-2822.

Disclosure of Interest: None declared

DOI: 10.1136/annrheumdis-2017-eular.4519

\section{AB1216-HPR THE EFFECTS OF APPLICATION OF IONTOPHORESIS AND PHONOPHORESIS IN PATIENTS WITH SUBACROMIAL IMPINGEMENT SYNDROME}

A. Yildiz ${ }^{1}$, E. Kusan ${ }^{2} .{ }^{1}$ Physiotherapy and Rehabilitation, Marmara University Health Sciences Faculty; ${ }^{2}$ Physiotherapy and Rehabilitation, Kosuyolu Medipol Hospital, Istanbul, Turkey

Background: Subacromial impingement syndrome (SIS) is defined as the mechanical compression of subacromial structures between the coraco-acromial arch and the humerus during active elevation of the arm above shoulder height. Objectives: The aim of the study was to investigate the effects of applications of iontophoresis and phonophoresis, which has been used in addition to physiotherapy program on pain and disability level in patients with SIS.

Methods: The study was conducted with subjects $(n=43)$ diagnosed with SIS. The subjects were divided into two groups randomly as iontophoresis group (IG) and phonophoresis group (PG). Diclofenac sodium iontophoresis was applied to the first group $(n=22)$, diclofenac sodium phonophoresis was applied to the second group $(n=21)$. In addition all of groups therapy program includes superficial heat, transcutaneous electrical nerve stimulation and exercise. The groups were evaluated before and after treatment in terms of pain and scores of shoulder disability. Visual analog scale was used to assess of pain (night pain, rest pain, pain with motion and pain in functional use), Shoulder Disability Questionnaire (SDQ) and Disabilities of the Arm Shoulder and Hand (DASH) were used to assess of shoulder disability.

Results: 43 patients with IS aged 18 to 65 years were recruited to the study. Demographic data were similar in the groups.

After treatments pain severity (night pain and pain in functional use) was significantly decreased in both groups $(p<0,05)$ and in the scores of disability of shoulder $(p<0,05)$ in both groups. Pain relief was similar in groups. SDQ and
Table 1. The level of pain, functionality and disability scores in groups

\begin{tabular}{|c|c|c|c|c|c|c|}
\hline & \multicolumn{2}{|c|}{ IG } & \multirow[t]{2}{*}{$\mathrm{p}$} & \multicolumn{2}{|c|}{$P G$} & \multirow[t]{2}{*}{$\mathrm{p}$} \\
\hline & $\begin{array}{c}\text { Before } \\
\text { mean } \pm \mathrm{sd}\end{array}$ & $\begin{array}{c}\text { After } \\
\text { mean } \pm \text { sd }\end{array}$ & & $\begin{array}{c}\text { Before } \\
\text { mean } \pm \mathrm{sd}\end{array}$ & $\begin{array}{c}\text { After } \\
\text { mean } \pm \text { sd }\end{array}$ & \\
\hline Night pain severity & $5,59 \pm 3,01$ & $1,77 \pm 1,99$ & * & $4,47 \pm 2,42$ & $1,42 \pm 1,8$ & * \\
\hline Severity of general pain & $5,09 \pm 2,13$ & $2,63 \pm 1,59$ & * & $4,52 \pm 1,72$ & $2,28 \pm 1,45$ & * \\
\hline SDQ & $48,00 \pm 20,75$ & $22,36 \pm 20,41$ & * & $50,12 \pm 21,18$ & $19,35 \pm 15,84$ & * \\
\hline DASH & $38,90 \pm 14,74$ & $19,63 \pm 9,37$ & * & $41,57 \pm 9,53$ & $22,64 \pm 10,37$ & * \\
\hline
\end{tabular}

IG: Iontophoresis group, PG: Phonophoresis group. ${ }^{*} \mathrm{p}<0,001$

DASH scores were improved in two groups after treatments. But there was no difference between the groups in terms of functionality and disability scores.

Conclusions: This study shows that diclofenac sodium iontophoresis and phonophorosis that are used in patients with subacromial impingement syndrome have similar positive therapeutic effects on shoulder functions.

References:

[1] Kuhn JE. Exercise in the treatment of rotator cuff impingement: a systematic review and a synthesized evidence-based rehabilitation protocol. J Shoulder Elbow Surg. 2009 Apr;18(1):138-60.

[2] Sedeek SM et al. Subacromial impingement syndrome: review article. Hard Tissue 2013 Sep 28;2(4):39-43.

[3] Ozsahin M et al. Adaptation of the Shoulder Disability Questionnaire to the Turkish population, its reliability and validity. International Journal of Rehabilitation Research. 2008:31(3):241-45.

[4] Düger et al. Kol, omuz ve el sorunları anketi (Disabilities of the Arm, Shoulder and Hand - DASH) Türkçe uyarlamasının güvenirliği ve geçerliği. Fiyoter Rehabil. 2006;17(3):99-107.

Disclosure of Interest: None declared

DOI: 10.1136/annrheumdis-2017-eular.4883

\section{AB1217-HPR THE EFFCET OF ADDING WII FIT ${ }^{\circledR}$ GAMES TO TRADITIONAL REHABILITATION ON PAIN, QUALITY OF LIFE AND FUNCTIONALITY AFTER ACL RECONSTRUCTION}

Z.B. Karakoç, T. Kuru Çolak, B. Kapssigay, Z. Sarı, M.G. Polat. Physical Therapy and Rehabilitation, Marmara University Health Science Institute, Istanbul, Turkey

Background: Wii Fit ${ }^{\circledR}$ games are widely used in the rehabilitation field due to their audiovisual feedback and motivating effect (1). Although it is well known that Wii $\mathrm{Fit}^{\circledR}$ games improve the quality of life in various groups $(2,3)$, there is no study on those who have undergone anterior cruciate ligament (ACL) arthroscopic surgery. Objectives: The aim of this study was to determine the effect of Wii Fit ${ }^{\circledR}$ games on pain, quality of life and lower extremity functionality after ACL reconstruction. Methods: Patients who underwent arthroscopic ACL reconstruction surgery in Kartal Dr. Lutfi Kırdar Training and Research Hospital were included in this study. Being volunteer for this study, not receiving any other treatment after surgery and being in the first 6 months after surgery were determined as inclusion criteria. Having any orthopaedic injury or congenital deformitiy and having vision, balance or neurologic problems were defined as exclusion criteria. After recording demographic data patients' pain, quality of life and lower extremity functionality were evaluated with "Visual Analog Scale (VAS)", Anterior Cruciate Ligament Quality of Life (ACL-QoL) Scale and "Lower Extremity Functionality Scale (LEFS)", respectively.

Patients received accelerated rehabilitation program 3 days per week, for 6 weeks. Wii $\mathrm{Fit}^{\circledR}$ games has added to accelerated program for 40 minutes in every treatment sessions in the last three weeks. Assessments were performed the baseline 3th week and, end of the treatment. The SPSS v11.5 was used for data analysis.

Results: Twelve males with a mean age of $29 \pm 8,51$ years were included in this study. Their average body mass index, time between injury and surgery and time between surgery and the beginning of rehabilitation were $25,82 \pm 2,85 \mathrm{~kg} / \mathrm{m}^{2}$, 374 days and $30 \pm 42,62$ days, each seperately. Pain improved significantly during the treatment $(\mathrm{p}=0.012)$. The quality of life level increased significantly at the end of the study compared to the 3 th assessment $(p=0.041)$. Lower extremity functionality improved during the rehabilitation $(p=0.003)$.

Conclusions: Patients participating in this study expressed $\mathrm{Wii} \mathrm{Fit}^{\circledR}$ games as funny and easy method to utilize. Wii $\mathrm{Fit}^{\circledR}$ games are suitable for use in patients who have had ACL arthroscopic surgery.

\section{References:}

[1] Minyoung L, Dongwon S, Jaebum S, Jungjin K, Seon-Deok E, BumChul Y. Patient perspectives on virtual reality-based rehabilitation after knee surgery: importance of level of difficulty. Journal of Rehabilitation Research and Development. 2016; 53 (2): 239-52.

[2] Hammond, J., Jones, V., Hill, EL., Green, D., Male, I. An investigation of the impact of regular use of the Wii Fit to improve motor and psychosocial outcomes in children with movement difficulties: a pilot study. Child: care, health and development. 2014; 40 (2): 165-175.

[3] Plow, M., Finlayson, M. Potential benefits of Nintendo Wii Fit among people with multiple sclerosis: a longitudinal pilot study. International journal of MS care. $2011 ; 13(1): 21-30$

Disclosure of Interest: None declared

DOI: 10.1136/annrheumdis-2017-eular.6105 